\title{
PARAGUAY DESPUÉS DEL GOLPE: EL PRECIO DE PONERSE COLORADO
}

\author{
Félix Pablo Friggeri ${ }^{1}$
}

\section{INTRODUCGIÓN}

La vUelta Al PODER de LA Asociación Nacional Republicana (Partido Colorado) en Paraguay en 2013 tiene una significación política relevante tanto para la realidad interna de este país como para el proceso de integración latinoamericana.

Desde allí, aun guardando un cuidado especial en las apariencias, el viejo Partido-Estado que ocupara ininterrumpidamente el poder por 61 años $^{2}$ ha venido fortaleciendo las estructuras de dominación aún vivas del stronismo, ${ }^{3}$ maquilladas de cierto formalismo institucional y con una política neoliberal respetuosa de los intereses oligárquicos internos. De esta manera, se entiende que se podría hablar de un "stronismo globalizado", o sea, del reverdecimiento de una vieja estructura socio-política interna al servicio de los intereses supuestamente "globalizadores" que son fundamentalmente

${ }^{1}$ Esta investigación se llevó a cabo en el marco de la labor del Observatorio de la Realidad Campesina e Indígena del Paraguay (ORCIP) con quien se realizó el trabajo de campo. En una de las entrevistas participó, también, la estudiante Malaika Yanou de la Universitá di Bologna.

${ }^{2}$ José Carlos Rodríguez, "El cambio frágil del Paraguay. La esperanza y las dificultades de Fernando Lugo”, Nueva Sociedad, núm. 220, 2009, p. 4.

${ }^{3}$ Se suele denominar "Stronismo" al régimen instaurado por el General Alfredo Stroessner quien gobernó el Paraguay ininterrumpidamente desde 1954 hasta 1989. También, por extensión, al estilo de gobierno de dominación dictatorial bajo ciertas formalidades democráticas que instauró y que marcó fuertemente la cultura política del país. 
expresión de la política norteamericana. La vigencia de estas ominosas estructuras y su reciclamiento en este tiempo latinoamericano cobran gran valor - político y simbólico- tras haber superado con vitalidad un periodo de signo contrario - el accidentado y constreñido periodo luguista, ${ }^{4}$ que poco pudo inmutarlas- y otro periodo de su viejo "adversario" electoral, pero compañero de negociados y de ideología política: el golpista liberal. ${ }^{5}$ Así entendido este proceso es básicamente "el retorno a un pasado marcado por la injusticia social y el patrimonialismo político"; 6 pero ese retorno acontece basado en una continuidad establecida por la vigencia de "la organización de la dominación bajo formatos democráticos" que articuló el stronismo, ya que tanto la dictadura paraguaya, como algunas dictaduras centroamericanas funcionaron "recreando ingenierías políticas 'liberales' que, articuladas en redes personales y familiares, tendieron a perdurar inclusive más allá de la figura en el poder que los aglutinaba". ${ }^{7}$ Es que Stroessner podía llamar públicamente "democracia" a su régimen, justamente porque en la experiencia paraguaya la única democracia conocida era la formal, procedimental.

Un segundo aspecto de este panorama político que se presenta en Paraguay es el del proceso de la integración latinoamericana y, especialmente, en cuanto a su fundamental -y diría "fundacional"dimensión contrahegemónica, que ha sido la clave para su inédito

${ }^{4}$ Por "periodo luguista" me refiero al que gobernó como presidente Fernando Lugo entre 2009 y 2012 cortando esos 61 años de presidencias coloradas. El gobierno de Lugo fue destituido por un golpe parlamentario-judicial en junio de 2012, asumiendo el gobierno su vicepresidente: el liberal Federico Franco.

${ }^{5}$ El Partido Liberal es, junto al Colorado, uno de los dos grandes partidos tradicionales del Paraguay provenientes del siglo xix. En 1978 se creó el Partido Liberal Radical Auténtico, que terminó absorbiendo al viejo partido bajo la consigna de recuperar sus banderas históricas en plena era stronista. A pesar de haber contado con distintas corrientes y personajes célebres, varios de los cuales tuvieron una fuerte impronta social, hoy en día su orientación política es claramente oligárquica y neoliberal difícil de distinguir de la del coloradismo.

${ }^{6}$ Richer, "Seis preguntas y seis respuestas sobre la crisis paraguaya", Nueva Sociedad, núm. 241, 2012, p. 4.

${ }^{7}$ Lorena Soler, "Dominación política y legitimidad. El stronismo en el contexto de América Latina”, NovaPolis, núm. 4, 2009, p. 84. 
avance. De alguna manera, con la asunción del gobierno colorado, este proceso se ha recompuesto formalmente, pero está incubada una fuerte tensión política con la entrada en el bloque mercosuriano de un gobierno claramente disonante con la línea política diseñada en los últimos años en este organismo. ${ }^{8}$ Dos aspectos de esa disonancia son: el papel que tiene Estados Unidos al colocar, con el nuevo gobierno, un ariete a su servicio en el corazón de Sudamérica y lo que sigue ocurriendo con las comunidades campesinas e indígenas que vienen siendo violentamente atacadas -de la mano del agronegocio $^{9}$ - y cuya prospectiva sigue siendo un periodo de total desprotección y de amenaza impune. Son dos elementos de posible desestabilización regional que no pueden dimensionarse totalmente por ahora.

El SIGNIFICADO DE LAS ELECGIONES DE 2013

La calidad democrática de estas elecciones estuvo en proporción directa a la expectativa que las propuestas políticas ofrecieron. Una afirmación del bipartidismo oligárquico-clientelista, tan larga y dolorosamente conocido por los paraguayos como para esperar bien poco de él, fue posible, entre otras cosas, por la ineptitud de la izquierda ${ }^{10}$ para construir una alternativa posible y confiable.

Así, la izquierda configuró una decepción clara en cuanto a su capacidad electoral. Esta incapacidad presenta varias facetas. Una

${ }^{8}$ En la fase final de la redacción de este artículo, fue elegido Mauricio Macri como presidente en Argentina. Sin duda, el presidente paraguayo Horacio Cartes encontrará una mayor afinidad en este gobierno, pero la repercusión en el conjunto del Mercosur es difícil de evaluar todavía.

${ }^{9}$ Claudia Korol, "Paraguay, la resistencia popular y las guerras del imperio", América Libre, 2006.

${ }^{10}$ Por "izquierda" en Paraguay entiendo, en estos últimos años, un conglomerado de pequeños partidos y movimientos sociales con distintas orientaciones ideológicas cuyo aglutinante mayor fue el Frente Guasú que lanzó la candidatura de Lugo. Con relativa importancia también están también otros grupos que promovieron la abstención o no participaron del proceso electoral, entre ellos se destaca el Partido Paraguay Piahura que expresa fundamentalmente una parte importante de la dirigencia del importante Frente Nacional Campesino (FNC). 
primera es la de no haber podido aprovechar una oportunidad única: tras el golpe de 2012 Fernando Lugo superaba claramente $40 \%$ en cuanto a apoyo popular ${ }^{11}$ y el rechazo a semejante atropello a la democracia rondaba $60 \%$. Lugo, sin embargo, era en ese momento, y sigue siendo, el político que más confiabilidad -dentro de los límites de un ambiente profundamente reticente en este sentido-suscita en el país, pero no tuvo la capacidad de traducirlo electoralmente con claridad. Cuando la izquierda tuvo la oportunidad de presentarse como una alternativa presidencial por sí misma o, por lo menos, como un bloque de poder que tuviera peso real en el poderoso parlamento, dejó pasar esta oportunidad. Hubo demoras y desacuerdos, donde primaron intereses individuales por sobre una conciencia de lo colectivo; limitaciones en la comunicación con las bases populares urbanas y rurales y una concomitante incapacidad de movilizar a la población ${ }^{12}$ aún con pocos recursos; sin una base teórica suficientemente clara y profunda. ${ }^{13}$ Todo esto permitió que se abrieran grietas amplias en el mismo Frente Guasú $^{14}$ y que se alcanzara una realidad electoral demasiado pobre y desproporcionada al grado de desprecio y antipatía por la política tradicional existente en el pueblo paraguayo. Hoy, el actual presidente, Horacio Cartes podría repetir aquello que solía decir Alfredo Stroessner: "él no estaba en su cargo sólo gracias a sus aciertos, sino también a los errores de sus adversarios". ${ }^{15}$

Con el camino allanado, las estructuras más que centenarias, pero vivas, del bipartidismo oligárquico fueron aceitadas con lo que en ese inédito momento macroeconómico abundaba: el dinero.

${ }^{11}$ Diego Abente Brun, "Paraguay: Crecimiento económico, conflicto social e incertidumbre política”, Revista de Ciencia Política, vol. 32, núm. 1, 2012, p. 243.

12 Atilio Borón, “¿Por qué cayo Lugo?”, Página/12, Buenos Aires, 24 de junio de 2012.

${ }^{13}$ Richer, Paraguay: fin de un periodo histórico, Asunción, BASE Investigaciones Sociales, 2008, p. 18.

${ }^{14}$ Abente, op. cit., p. 235. La agrupación política que se concentró en el apoyo al liderazgo de Fernando Lugo y lo llevó al poder en alianza con el Partido Liberal y un grupo de otros pequeños partidos y movimientos sociales. Guasú es una palabra guaraní que podría traducirse como "grande".

${ }^{15}$ Benjamín Arditi, "Adiós a Stroessner: nuevos espacios, viejos problemas", Nueva Sociedad, núm. 102, 1989, p. 25. 
Dinero del Estado (más usado por los perdedores del Partido Liberal que confiaban en él para ganar, ipor fin!, alguna elección después de tanto tiempo) y dinero privado (usado por los dos, pero concentrado en el capital y los "contactos" patronales del propio candidato triunfante). Así, con mucho dinero, las dos estructuras funcionaron, pero funcionó mejor la largamente más extendida y organizada a fuerza de tiempo y violencia por el viejo Stroessner: el coloradismo. Ninguno de los dos puso grandes ideas ni propuestas. Lo más destacado que pusieron fueron entrecruces de denuncias que evidenciaban que además de competir electoralmente, compiten en la magnitud de la corrupción que los atraviesa. Y hay que reconocer que, para lo que querían, les fue bien. En un ámbito de desaliento, desmovilización e impotencia, el aparato clientelar cargado de dinero es casi imbatible.

\section{STronismo GLOBALIZAdo}

La articulación del golpe parlamentario-judicial por parte de Cartes fue denunciada por el expresidente Lugo, pero también expresamente admitida por publicaciones del mismo "palo" como la insospechable de cualquier izquierdismo revista brasileña Veja. Esta publicación deja en claro que el objetivo del golpe era mejorar las oportunidades del triunfo electoral de Cartes. Además presenta su plan de gobierno con las mismas palabras acusatorias a Lugo con las que justificó el golpe: falta de seguridad para los laboriosos colonos brasiguayos ${ }^{16}$ a los que hay que cuidar del terror y muerte que siembran los sin tierra ligados al presidente. ${ }^{17}$ Ninguna referencia se hizo, por supuesto, al formidablemente mayor caudal de terror y muerte que han causado los mismos terratenientes y sus

${ }^{16}$ Se denomina "brasiguayos" a los colonos brasileños que se establecieron en Paraguay sobre todo a partir del avance transestatal de la frontera agrícola del Brasil hacia - principalmente- el este paraguayo. Aunque se trata de un fenómeno socialmente complejo, las referencias que hago en el trabajo toman a este colectivo sobre todo desde sus sectores más poderosos.

${ }^{17}$ Carolina Freitas, "Partido Colorado: 'A saída de Lugo foi queda de um modelo’”, Veja, São Paulo, 26 de junio de 2012. 
mercenarios contra el campesinado y las comunidades indígenas, ni a la seguridad de estos ciudadanos paraguayos, que parecerían no contar en sus preocupaciones.

Aunque el "golpe de clase de la oligarquía"18 devino en un gobierno liberal, esta ocasión favoreció electoralmente más la acción de la maquinaria colorada (tradicionalmente insertada en las estructuras estatales y militares) henchida del dinero, de dudosísima procedencia, que le aportó su candidato. ${ }^{19} \mathrm{El}$ mismo presidente uruguayo, José "Pepe" Mujica, popularizó el concepto de "narcocoloradismo", y la relación a Cartes -aunque no sólo a él- aparece obvia por sus antecedentes.

Aun con esta novedad -del origen principalmente privado del aceitamiento financiero de aquella maquinaria-, la fórmula, tanto para la campaña electoral como para lo que puede preverse del futuro gobierno, es un reciclamiento del stronismo: "Es el Modelo Cartes \& CIA, modelo que se sustenta sobre la fascinación por el dinero, el tráfico de influencias, la conciliación entre la mafia y el sistema financiero, la corrupción pública y privada, la explotación de trabajadoras y trabajadores, la exclusión de millones de personas, el saqueo de recursos naturales, todo esto al servicio del imperialismo norteamericano y su lógica predatoria. Es la versión moderna del Modelo Stroessner \& CIA". ${ }^{20}$

No sería muy distinto si el triunfo hubiera correspondido a la alianza (formada a última hora y entre escándalos de corrupción) de liberales y oviedistas: "liberales y colorados sólo se diferencian por el color del pañuelo. Ambos candidatos prometen un gobierno aséptico con respecto a los problemas sociales, con una gestión frente al Estado que será más bien la de un gerente de empresa antes que la de un estadista. Efectivamente, Alegre no tiene los

${ }^{18}$ Richer, "Seis preguntas y seis respuestas sobre la crisis paraguaya", p. 6.

${ }^{19}$ Horacio Cartes aparece con un largo historial por el cual es vinculado al lavado de dinero, al narcotráfico y al contrabando. Una descripción, entre muchas, de estos antecedentes puede verse en Karl Schurster y Márcio Oliveira de Brito, "Entre a Alternância e a Hegemonia Política: o Paraguai no Tempo Presente”, Boletim Historiar, núm. 02, 2014, pp. 0718.

${ }^{20}$ Najeeb Amado, “Modelo Cartes y razón de Argaña”, E’A. Periódico de Interpretación y Análisis, Asunción, 6 de abril de 2013. 
antecedentes oscuros de Cartes, pero el entorno de ambos nos asegura que el Estado clientelar, prebendario, o sea, corrupto, seguirá medrando". ${ }^{21}$

Cartes principalmente, aunque también los liberales, son una manifestación de lo que denomino neooligarquías: una semi-renovada versión de las oligarquías latinoamericanas decimonónicas que incorporan especialmente la fuerza del proceso de reprimarización de la economía -emblematizado en el Cono Sur en el agronegocio- y de los medios de comunicación hegemónicos. ${ }^{22}$ Es

${ }^{21}$ Sergio Cáceres Mercado, "Como ovejas al matadero", Última Hora (Asunción), 15 de abril de 2013.

${ }^{22}$ Este concepto de "neooligarquías" expresa esa mixtura -fuertemente vigente hoy- con un carácter oligárquico que tienen nuestras democracias y que se puede caracterizar como "el modo regular, habitual si no constante, en que los sectores establecidamente más ricos y poderosos ejercen o influyen como tales sobre el gobierno en dirección de sus propios intereses de grupo privilegiado" (Carlos Strasser, Democracia Ẽ Desigualdad. Sobre la "democracia real" a fines del siglo Xx, Buenos Aires, CLACSO, 1999, pp. 58-59). El planteamiento neoliberal reactualiza la dominación oligárquica en sus líneas fundamentales con algunas variantes de peso como es la importancia de los medios de comunicación que ha crecido enormemente. Es una mixtura de empresariado y clase política enlazada al capital transnacional que conforma este tipo de dominación. Es bueno ver la caracterización que hace Ansaldi ("Frívola y casquivana, mano de hierro en guante de seda. Una propuesta para conceptualizar el término oligarquía”, 1991) de la dominación oligárquica, para ver cómo -exceptuando la determinación histórica que él sostiene- sus características se presentan nítidamente en la actualidad. La relación a los medios de comunicación hegemónicos es clave. En Paraguay es "un sector altamente concentrado en pocos grupos empresariales propietarios de varias empresas, integradas en complejos multimedios [...] fundamental y estratégico para la imposición de ideas y el control ideológico de la población y, en consecuencia, la reproducción del sistema económico y la conservación de los beneficios que de él se derivan” (Luis Rojas Villagra, La metamorfosis del Paraguay. Del esplendor inicial a su traumática descomposición, Asunción, BASE-IS /Fundación Rosa Luxemburgo, 2014, p. 110). Sobre el papel de los medios en la justificación de la represión al campesinado puede verse: José Tomás Sánchez, "El campesino paraguayo es pobre porque es ignorante. El discurso legítimo de los medios escritos de comunicación y la lucha por la tierra”, en Marielle Palau (coord.), Criminalización a la lucha campesina, Asunción, BASE-Is / Fundación Rosa Luxemburg, 2009, pp. 103-133. Sobre la relación entre el poder de los medios y la dominación norteamericana en el país puede verse Cristina Coronel et al., USAID en Paraguay. La asistencia como estrategia de dominación, Asunción, BASE-IS/Fundación Rosa Luxemburgo, 2012, pp. 23-76. Sobre la relación de los 
interesante cómo Méndez Grimaldi ${ }^{23}$ destaca la vinculación de Cartes con la UGP (Gremio patronal de los productores del agronegocio) personalizada especialmente en su presidente Héctor Cristaldo, que llegó a ser precandidato a legislador en sus listas, y con el Grupo Zucolillo (del diario ABC Color y demás). Sus objetivos podrían ser admirablemente resumidos en este párrafo que analiza el porqué del golpe parlamentario:

Los objetivos estratégicos son: reinstalación de una democradura exclusivamente regenteada por la derecha, con apoyo de Estados Unidos y algunos países europeos como en los tiempos de la guerra fría; arrinconamiento y criminalización de la izquierda y los movimientos sociales; avance de la producción meramente extractivista agroexportadora, con la postergación indefinida de la industrialización del país; consolidación violenta del proceso de descampesinización del campo. ${ }^{24}$

En cuanto a las características de este stronismo reciclado que aparece como horizonte político en Paraguay, planteo, seguidamente, algunos de sus elementos constitutivos. Un primer elemento es lo que calificaría de "dupla omnipotencia dominadora / impotencia popular". Ya Arditi ${ }^{25}$ refería este binomio a Stroessner quien recicló este imaginario -de fuerte presencia histórica en el país- de una manera magnífica: con una gran dosis de violencia y una dosis contemporizadora de paternalismo patronal -"hábil mezcla de cooptación y represión" ${ }^{26}$-, instaló en buena parte de la población el sentimiento de que nada se podía sin él, y, mucho menos, contra

medios con la oligarquía paraguaya y las dificultades del trabajo periodístico: Julia Varela y Federico Larsen, "El trabajo periodístico en Paraguay: el golpe de Estado en 2012 y los medios de resistencia al discurso hegemónico”, Oficios Terrestres, vol. I, núm. 29, 2013. Sobre el papel reaccionario de los medios en el golpe: Diego Segovia, "Paraguay 2013: los medios y el consenso reaccionario", Perspectivas, núm. $13,2013$.

${ }^{23}$ Idilio Méndez Grimaldi, "Los intereses convergentes que derrocaron a Lugo", La Jornada, 25 de junio de 2012.

${ }^{24}$ Loc. cit.

${ }^{25}$ Arditi, op. cit., p. 25.

${ }^{26}$ Robert Andrew Nickson, "El régimen de Stroessner (1954-1989)", en A. V., Historia del Paraguay, Asunción, Ignacio Telesca, 2010, p. 271. 
él. Sus mercenarios dotaron a la violencia contra cualquier oposición -real y supuesta- de un carácter simbólico: lenguas y testículos cortados, fusilamientos masivos e inmediatos que abarcaron hasta niños, cadáveres mutilados tirados al Paraná para que puedan ser vistos como ejemplo por la población, violaciones y ratas en los úteros, y un largo etcétera. Todo se sumó para realizar una violencia pedagógica que instalara en el imaginario popular aquella dupla políticamente efectiva. Un matiz que puede verse en la versión actual del modelo es que la violencia continúa aunque relativamente más focalizada en sus manifestaciones más extremas como son los asesinatos. En este sentido, las dos manifestaciones más claras son, por un lado, la represión en el norte encuadrada en el accionar de la Fuerza de Tarea Conjunta que presenta siempre las muertes de campesinos como pertenecientes a los supuestos grupos guerrilleros. Por otro lado, están las continuos asesinatos de dirigentes campesinos cuyos responsables nunca aparecen ${ }^{27}$ y también algunas muertes de periodistas, en las que a lo sumo aparecen ciertos supuestos responsables inmediatos y no sus vinculaciones en sectores de poder más alto. ${ }^{28}$ Por otro lado, la referencia clave de la dominación ahora no está centrada tanto en un culto a la personalidad -como en el caso de Stroessner- sino más unida a lo invencible que son los poderes económicos que representan el progreso y que aparecen como irrefrenables. Más que una figura, parece imponerse que "acá manda la plata". En estos tiempos, más económicamente globalizados, la posesión del dinero y el manejo de los recursos económicos aparecen -aún sin descartar totalmente aquella "metodología pedagógica”- como un elemento mucho más efectivo y más potable políticamente. Y nada mejor que esa dupla la revitalice Cartes, uno de los empresarios más ricos del Paraguay. Una expresión de esta dupla fue lo que pasó en el momento del golpe. La impotencia popular en la defensa de la democracia fue acrecentada por la moderación de Lugo en esa coyuntura y por las débiles

27 Coordinadora de Derechos Humanos del Paraguay (CODEHupy), Informe Chokokue 1989-2013. El plan sistemático de ejecuciones en la lucha por el territorio campesino, Asunción, SV Servicios Gráficos, 2014.

28 Lorena Soler y Gustavo Torre, "Balance del gobierno del empresario Horacio Cartes en Paraguay”, CELAG, 2015. 
medidas punitivas del Mercosur. Las elecciones evidenciaron ese desencanto: Cartes y Alegre, ${ }^{29}$ lejos de cualquier tipo de liderazgo popular, con la compra del voto como plataforma para sus variados negocios, lograron un contundente "triunfo" en medio de la desilusión y el desaliento.

Otra característica del stronismo es el famoso "triángulo conformado por las Fuerzas Armadas, el Partido Colorado y el gobierno, con la figura del líder operando como su eje articulador" ${ }^{30} \mathrm{o}$ "alianza tripartirta" ${ }^{31}$ ¿Se repetirá esto? Las Fuerzas Armadas y de seguridad interna vienen recibiendo -incluso durante el periodo Lugo- una continua "capacitación" por parte de Estados Unidos y de sus ahijados militares colombianos. ${ }^{32}$ Esto provoca que su presencia en los conflictos sociales siga marcada por un accionar antipopular, aunque su injerencia en la alta discusión política aparezca mucho más acotada. La utilización del segundo elemento de la tríada, el coloradismo, por parte de Stroessner fue una jugada fuertemente efectiva ya que éste le proveía "de una base de identificación nacional, una penetración institucional y territorial, de la cual carecía el propio Estado-nación". ${ }^{33}$ Ahora, el Partido Colorado le brinda su penetrante y expandida estructura a un mecenas-candidato sin militancia, ni pertenencia a su estirpe histórica (como la que era entonces su presidenta y la mayoría de sus principales dirigentes). Por eso no llama la atención que el discurso triunfal de Cartes en la noche de elecciones haya sido una declaración de amor al Partido al cual se afilió hace apenas tres años. Lo que Cartes no tiene de carisma y liderazgo -tampoco Stroessner lo tenía tan claramente, ya que no era "la imagen estereotipo del caudillo

${ }^{29}$ Efraín Alegre fue el candidato del Partido Liberal Radical Auténtico (PLRA) en las elecciones presidenciales de 2013. Quedó en segundo lugar.

${ }^{30}$ Arditi, op. cit., p. 25.

${ }^{31}$ Nickson, op. cit., p. 279.

${ }^{32}$ Marielle Palau, "Los intentos del Plan Colombia para seguir avanzando en Paraguay", en Marielle Palau (coord.), Criminalización a la lucha campesina, Asunción, BASE-IS /Fundación Rosa Luxemburgo, 2009, pp. 31-33; Korol, op. cit.; Valentina Obando Jaramillo, "Colombia entrena paraguayos para combatir el EPP", El Espectador (Bogotá), 8 de agosto de 2015.

${ }^{33}$ Soler, "Dominación política y legitimidad...", p. 80. 
latinoamericano"34_ lo suple con el dinero y con la imagen de patrón exitoso. Claro que esta imagen perdurará mientras esté lo primero y sepa ser un articulador de los coincidentes intereses del reducido y multifacético sector oligárquico. La ausencia actual muerto Lino Oviedo ${ }^{35}$ - de cualquier otro proyecto individual de derecha con posibilidades de discutirle el poder le da una garantía coyuntural de "gobernabilidad" como articulador y guardián de aquellos intereses. El gobierno de Cartes, en una continuidad parcialmente renovada de las tradiciones stronistas en las Fuerzas Armadas, refuerza la identificación de éstas con el modelo norteamericano de Seguridad Nacional desde su versión posterior al 11 de septiembre de $2001,{ }^{36}$ donde se va diluyendo la distinción entre los conceptos de Defensa y Seguridad para involucrar a las Fuerzas Armadas en supuestas tareas policiales de seguridad interior vía una identificación con el modelo colombiano, asimilando las fuerzas minúsculas -en caso de existir- del EPP y la $\mathrm{ACA}^{37}$ con las

${ }^{34}$ Nickson, op. cit., p. 280.

35 Lino Oviedo era un militar que adquirió notoriedad por su participación en la acción que termina derrocando a Stroessner. Influyente en algunos sectores militares y capaz en la comunicación con sectores populares, organizó una escisión en el coloradismo (la UNACE) que tuvo bastante fuerza política en algún momento. Murió llamativamente en un accidente aéreo el día del aniversario del golpe contra Stroessner en plena campaña para la presidencia en 2013.

${ }^{36}$ Se entiende que el planteo post 11 de septiembre de la Seguridad Nacional desde Estados Unidos guarda líneas nucleares de continuidad con la Doctrina de Seguridad Nacional que dominó entre los sesenta y los ochenta, fundamentalmente. Cf. Silvina Romano, "Democracia liberal y seguridad nacional en el gobierno estadounidense: continuidades y rupturas", en Marco A. Gandasegui, hijo y Dídimo Castillo Fernández (coords.), Estados Unidos: la crisis sistémica y las nuevas condiciones de legitimación, México, CLAcso-Siglo XXI, 2010, pp. 360-384.

${ }^{37}$ Se trata del llamado Ejército del Pueblo Paraguayo (EPP), una supuesta -y de ser real, pequeñísima- organización armada que tiene su actuación, fundamentalmente, en los departamentos norteños de San Pedro y Concepción... La mención al EPP ha funcionado, de hecho, como una bandera de estigmatización de las luchas campesinas y una base para intentar legitimar su brutal represión y la constante intimidación ante cualquier proceso organizativo autónomo. Sobre esta supuesta existencia fue planteada la justificación de la modificación de la Ley de Defensa Nacional y Seguridad Interna dando lugar a la "vigencia de un estado de excepción de facto, sin límite temporal” (Liliana Rocío Duarte Recalde, 
multitudinarias y experimentadas FARC. ${ }^{38}$ Esto posibilita también, mediante la apelación a la invocada amenaza "terrorista" a nivel planetario, crear un imaginario de modernización de las Fuerzas Armadas, ubicadas en una lucha "compartida" con los militares más poderosos del planeta y sus más cercanos discípulos actuales en la región. Se sostiene que en el pensamiento estadounidense de alguna manera se sustituye al enemigo "comunista" de la Guerra Fría y de la primera Doctrina de Seguridad Nacional por otro enemigo resumido en el término "eje del mal" mucho más maleable que el anterior. En Paraguay se superponen ambos justamente por la fuerte vigencia del stronismo que encuentra una síntesis de estos dos "tipos de enemigos" en las supuestas organizaciones guerrilleras y, por intencionada extensión, en el campesinado organizado que lucha por la tierra y por otro modelo productivo y político. Esto no es nuevo porque repite el esquema stronista, pero es claramente adecuable a los planteos actuales de injerencia norteamericana en la región con participación de las fuerzas armadas y de seguridad locales a quienes se "eleva" a la condición de "soldado universal". Unido a este imaginario está el del progreso de la civilización frente a los bárbaros que se resisten y pelean contra ella. Paraguay puede ser fácilmente ubicado como uno de los "estados

"Concentración del poder político y debilitamiento estatal durante el gobierno de Cartes”, Revista Novápolis, núm. 7, abril-octubre de 2014, p. 48). Una breve y muy interesante interpretación de la relación entre la mención al EPP y la represión al campesinado, hecho desde gente que trabaja hace mucho tiempo en la zona más afectada como es el Servicio Paz y Justicia Paraguay. Puede encontrarse en Irala, "Siete reflexiones en torno al asesinato del ganadero y la supuesta autoría del EPP", Servicio Paz y Justicia Paraguay, 2015. Cf. Sonia Winer y Lucas Melfi, "Guerra contra el Ejército del Pueblo Paraguayo: impacto durante el gobierno de Cartes”, VIII Jornadas de Sociología de la Universidad Nacional de La Plata, 2014. Un texto clave para entender el sentido de la utilización del supuesto EPP es: Hugo Javier Pereira Cardozo, El EPP, defensa reaccionaria de un modelo de desarrollo desigual y excluyente, Buenos Aires, CLACSO, 2015. En cuanto al ACA, que es la Agrupación Campesina Armada, es identificada como un minúsculo desprendimiento del EPP, con similar radio de acción y que, según la información oficial, ha sido recientemente desarticulada en su casi totalidad.

${ }^{38}$ Las Fuerzas Armadas Revolucionarias de Colombia (FARC) tienen más de cincuenta años de lucha y están compuestas presumiblemente por entre diez mil y quince mil miembros. 
fallidos" que pueden dar lugar al surgimiento del terrorismo y no tienen capacidad propia para enfrentarlo y por ello merecen ser espacios de desarrollo de "la guerra preventiva". ${ }^{39}$ Por esto quizás, las Fuerzas Armadas son uno de los elementos que aportan a que esta nueva versión del stronismo en Paraguay pueda llamarse "globalizado". He aquí una diferencia: la articulación entre Fuerzas Armadas ya no aparece tan ligada al Partido Colorado, sino principalmente a Cartes, y más aún a las corporaciones patronales, entre ellas las brasiguayas. El exministro asesor de relaciones internacionales Ruiz Díaz Balbuena sostiene que "el comandante en jefe [...] en teoría es Horacio Cartes pero en la práctica son los empresarios los que están manejando las Fuerzas Armadas paraguayas". ${ }^{40}$ Este empresariado no tiene hoy, predominantemente, como principal identificación, una filiación partidaria. En cuanto a la relación con el Partido Colorado, Cartes ha tratado de aprovechar la falta de liderazgos claros dentro del partido que posibilitó su emergencia y que lo mantiene como referente "por encima" de parte de las luchas internas, sin transformarlo en líder indiscutido, ni indiscutible. Aquí también hay una variante de la época original stronista.

Un tercer elemento tiene que ver con lo que en el stronismo era la articulación de corrupción / lógica clientelística /consenso pasivo: "La institucionalización de la corrupción, junto con la lógica clientelista del intercambio de favores por obediencia, sirvieron para generar un consenso pasivo cómplice para su gestión”. ${ }^{41}$ Las recientes elecciones fueron una inmejorable oportunidad de cerciorarse de la vigencia plena y perfeccionada de este aspecto del stronismo. Otra fuente insospechable de izquierdismo como el diario madrileño El País calificaba al Paraguay del 21 de abril como "el paraíso de la corrupción electoral" destacando que "en pocos lugares el negocio de la compra de votos alcanza tal grado de masificación y

${ }^{39}$ Juan Gabriel Tokatlian, "América Latina, China y Estados Unidos. Un triángulo promisorio”, Revista CIDOB d'Afers Internacionals, núm. 78, 2007, p. 190.

${ }^{40}$ Helena Marchini y Pablo Nuño Amoedo, entrevista al exministro paraguayo Hugo Ruiz Díaz Balbuena: "Paraguay está hoy subordinado a los intereses de los Estados Unidos”, América Latina en movimiento, 3 de agosto de 2015.

${ }^{41}$ Arditi, op. cit., p. 25. 
naturalidad", ${ }^{42}$ con todas sus prácticas de compra de células, de acarreos de votantes y corraleo de grupos y comunidades el día de la elección, entre otras. Esta articulación, admirablemente manejada, tuvo un resultado contundente en la reciente elección. El clientelismo -y mucho más, el clientelismo oligárquico- es indigno, habla de una infinita pobreza en cuanto democracia; pero hay que reconocer que electoralmente -y muy especialmente en estas situaciones- es efectivo. En la acción de gobierno, el coloradismo sigue intentando consolidar esta eficacia del clientelismo oligárquico haciendo reverdecer los tiempos en que "el partido oficial era la única fuerza política capaz de aliviar, a través de medidas parciales y clientelistas, los males causados por el propio gobierno" ${ }^{43}$

Un cuarto elemento es la configuración de una "oposición" moderada ${ }^{44}$ que permita un bipartidismo asimétrico. Este trabajo lo realizó -también con tiempo y violencia- el mítico don Alfredo. Y como en tiempos de él, esto se usa como "eslabón importante de su estrategia de legitimación, tanto en la arena doméstica como internacional"; el gran elemento legitimador es la "fachada democrática". ${ }^{45}$ Los liberales que contaron -siempre muy parcialmente- en sus filas con gente honorable y con cierta inclinación social, se fueron depurando de esa "anormalidad" a lo largo del tiempo de Stroessner, principalmente otorgando la descalificadora catalogación de "comunista" a todo aquel que no aceptara formar parte de una oposición legitimadora del régimen. Ya no quedan liberales que se interesen por la indispensable reforma agraria -como el viejo "Alón" 46 -, ni por una reforma impositiva que permita una distribución un poco más progresiva ${ }^{47}$ del alto ingreso que hoy tiene

${ }^{42}$ Francisco Peregil, "Paraguay, el paraíso de la corrupción electoral”, El País, 20 de abril de 2013.

43 José Carlos Rodríguez, "El cambio frágil del Paraguay. La esperanza y las dificultades de Fernando Lugo", Nueva Sociedad, núm. 220, 2009, p. 13.

${ }^{44}$ Arditi, op. cit., p. 26.

${ }^{45}$ Nickson, op. cit., p. 281.

46 "Alón" era el sobrenombre del líder liberal José de la Cruz Ayala, quien trabajó por la organización campesina a principios del siglo xx y cuyo nombre fuera reivindicado por las guerrillas liberales de los sesenta.

${ }^{47}$ La presión fiscal del Paraguay es sólo de $13 \%$ del PBI, y el impuesto inmo- 
el país. Hoy serían acusados de chavistas, bolivarianos o partidarios de la "Triple Alianza" (aunque lo de "comunistas"-en una casi ridícula supervivencia de macartismo de los tiempos de Guerra Fría- sigue apareciendo) con la colaboración de los medios de comunicación hegemónicos. Esta muy previsible solidaridad oligárquica del liberalismo con Cartes cuenta también con los agonizantes partidos UNACE ${ }^{48}$ y Patria Querida. Sólo queda esa izquierda minimizada electoralmente que describí más arriba. Frente a ella -y recordando los conceptos gramscianos- se multiplican los intentos de "cooptación molecular", y posiblemente algún intento de "cooptación orgánica” con los grupos más moderados como es tradición en la política oligárquica. ${ }^{49}$

Pero este modelo, que tiene su especificidad y algún grado de extremismo en Paraguay, también funciona - parcialmente- en otros países de la región que se presentan como de izquierda. Sin ser idéntico aparece con importantes similitudes con el de varios estados o provincias de los países mercosurianos que tienen gobiernos populares en la presidencia, pero gobernadores que bien merecerían una ficha de afiliación al coloradismo. La crítica al stronismo globalizado también tendría que servir para mirar dentro de las propias fuerzas que, por lo menos formalmente, integran una parte de los bloques de poder que sustentan a los gobiernos "populares" del resto de la región. Servirá para ver cómo se enfrenta esta verdadera incoherencia en el interior de países que proclaman una soberanía popular efectiva.

Es que el stronismo se presenta a los ojos de este tipo de políticos-provenientes de lógicas patronales- como un sistema de dominación efectiva al que no conviene dejar de lado así nomás. En

biliario -el que tendrían que pagar los terratenientes fundamentalmente- sólo aporta 0.04 de la presión tributaria, cuando sus ganancias producen $60 \%$ del PBI paraguayo. Sobre el fuerte carácter regresivo del sistema impositivo paraguayo $c f$. Duarte Recalde, op. cit., pp. 40-42.

${ }^{48}$ Es el Partido Unión Nacional de Ciudadanos Éticos que fundara y condujera hasta su muerte, al caer su helicóptero en plena campaña electoral del 2013, el militar Lino Oviedo. En 2015, dos hijos de Oviedo -que eran los únicos parlamentarios del partido-, junto a un importante número de dirigentes, pidieron su reincorporación al Partido Colorado, haciendo más evidente esa agonía.

49 Ansaldi, op. cit. 
general, esta lógica no tiene grandes preocupaciones éticas por la tortura, el sometimiento político, la pobreza, la degradación ambiental, la pérdida del campesinado, los derechos indígenas a su autodeterminación, la pérdida de soberanía. En su filiación ideológica al "darwinismo social", aparece como un padecimiento natural concomitante al grado de no adaptación a la lógica capitalista de las mayorías populares. Eso justifica que en el mismísimo portal electrónico del Partido Colorado aparezca como uno de los dirigentes históricos nada menos que Alfredo Stroessner sin absolutamente ninguna referencia crítica de su larguísimo paso por el poder ${ }^{50} \mathrm{O}$ que Cartes salga al cruce de un periodista de la derecha chilena para defender el periodo Stroessner como dotado de "signos de progreso y orden". ${ }^{51}$

El modelo no tiene ahora características de personalismo aberrante, conque no llegará a la categoría de "mito viviente" y "paralizador", ${ }^{2}$ no funcionará centrado exclusivamente sobre poder presidencialista sino en una coordinación cómplice con el poder del parlamento, pero sacando peleas internas por ambición de dinero y poder político. A nivel ideológico Cartes no tendría dificultades para manejar un legislativo que ya está predispuesto y acostumbrándose a que él lo maneje.

Un quinto elemento tiene que ver con el modelo económico, que podríamos caracterizar como de descampesinización / agronegocio / alto crecimiento macroeconómico / distribución regresiva del ingreso. Este modelo estuvo íntimamente ligado a la dependencia subimperialista de la dictadura paraguaya con respecto a la brasileña y fue marcado fundamentalmente por dos hechos: la construcción de la mega-represa binacional de Itaipú y la "Marcha hacia el Este". ${ }^{53}$ Tuvo su etapa principal en 1973-1980,

${ }^{50}$ ANR. Asociación Nacional Republicana. Partido Colorado, Líderes: Alfredo Stroessner. En el momento de las elecciones presidenciales de 2013, el nieto del dictador, Alfredo Gustavo Stroessner Domínguez, era Senador Nacional y miembro destacado de la Junta Nacional del Partido Colorado.

${ }^{51}$ El Mercurio, "Magnate paraguayo, favorito para las presidenciales, promete retorno al poder del Partido Colorado", Santiago de Chile, 24 de marzo de 2012.

${ }^{52}$ Arditi, op. cit., p. 25.

${ }^{53}$ La "Marcha hacia el Este", que comenzó a ser diseñada a fines de la década 
con que constituye lo que Nickson ${ }^{54}$ llama la "fase de expansión" del stronismo intrínsecamente ligada y dependiente del "Milagro brasileño". Paraguay acompañó dependientemente el comienzo del agronegocio -principalmente sojero- que inicia en América Latina el Brasil de la dictadura.

El sexto elemento, que analizo más abajo, es el ejercicio del poder colorado como "un aliado de las políticas imperiales", 55 con lo que contradice su autodefinición como "nacionalista".

\section{EL PROBLEMA DEL CAMPESINADO Y LOS PUEBLOS INDÍGENAS}

Paraguay, aún el porcentaje más alto de población rural de Sudamérica, tiene, también y especialmente por la conformación de esta población y por su cultura productiva, la enorme posibilidad de conformar un modelo alternativo de producción rural comunitaria en comunión con el medio ambiente. Semejante posibilidad no será aprovechada por este gobierno. Al contrario, lo que aparecía como probable y hoy puede comprobarse es un escenario de avance brutal del agronegocio a sangre y fuego -y esto no es una frase, es literalmente así- sobre las comunidades campesinas y las comunidades indígenas, y concomitantemente, un avance en la explotación destructora del medio ambiente.

de 1950, pero cuya ejecución abarcó las décadas posteriores, consistió en un plan político-económico de habilitar para las actividades agrícolas la zona oriental del país. Se planteó en principio desde la colonización privada que fundamentalmente estaba destinada a colonos extranjeros, y desde la colonización pública destinada a desconcentrar al campesinado paraguayo de la zona central del país y llevarlo a esta zona con el objetivo económico de que sean realizadas las primeras tareas que posibilitarían la actividad agrícola. La vulnerabilidad económica de la situación de estos campesinos -sumada a las tradicionales y actuales condiciones de inseguridad jurídica para los más pobres- posibilitó que, en no mucho tiempo, los campesinos "beneficiados" quedaran en una situación que facilitaría una reconcentración aún más pronunciada de la propiedad de la tierra. Una buena descripción de este proceso puede encontrarse en Rojas, op. cit., pp. 55-66.

${ }^{54}$ Nickson, op. cit., p. 271.

${ }^{55}$ Richer, Paraguay: fin de un período histórico, p. 5. 
El problema tiene varios aspectos que conviene destacar. El primero es el político. El campesinado y las comunidades indígenas en América Latina han sido el sujeto político más claramente revolucionario a lo largo de su historia regional. Las importaciones de teoría pretendidamente marxista que señalaron al proletariado urbano como sujeto principal de un proceso revolucionario hacia el socialismo han tenido pocas demostraciones prácticas en nuestro continente. El avance del agronegocio -fenómeno clave de nuestro Cono Sur- tiene también un derivado político que es difícilmente pensable como no deliberado: la eliminación del campesinado y de los pueblos indígenas como posible sujeto político revolucionario en América Latina. Al ritmo que avanza esto en Paraguay, el logro de este objetivo no demoraría demasiado. Para el gobierno colorado eso significaría la culminación de un viejo anhelo stronista: quedar sin ningún sujeto social de importancia que pueda transformarse en un sujeto político de oposición y de construcción de un modelo alternativo.

Este plan de exterminio tiene que ver con el logro de una simbiosis entre la oligarquía autóctona -que se caracteriza tanto por la variedad de sus negocios como por tener casi indispensablemente una faceta "terrateniente"-y el creciente poder brasiguayo. La fórmula que favorece a los dos se basa en los menores costos en el valor tanto de la tierra como de los impuestos para los brasileños instalados en el oriente paraguayo y en la posibilidad de tener ventas y arriendos de buen valor para la oligarquía local sobre todo teniendo en cuenta que su posesión se logró sin mayores costos para ellos, costos que se cargaron a la cuenta del Estado y de las comunidades campesinas e indígenas. A esto se suma el negocio del contrabando de cosecha desde Brasil a Paraguay que representa también una fuente de ingresos de muy buenos dividendos. Un último factor, que aparece cada vez con más claridad como fundamental: las operaciones de lavado de dinero y de narcotráfico que se esconden atrás de la fachada del agronegocio, operaciones por las que fuera imputado otrora el mismísimo actual presidente del Paraguay. La impunidad (frente a los negocios sucios y frente a la violencia) es el gran nicho ecológico de esta simbiosis.

El agronegocio brasiguayo también sirve como articulador de la política externa con Brasil. La tolerancia al atropello del 
campesinado y a los pueblos indígenas tiene que ver con los vínculos múltiples del agronegocio brasileño a ambos lados de la frontera. Conversando con algunos dirigentes sociales paraguayos que apoyaban el proceso luguista me decían que hubiera sido oportuno frente al golpe parlamentario el corte de toda relación con Paraguay, lo cual hubiera acarreado una caída prácticamente inmediata del gobierno de Federico Franco $^{56}$ y, posiblemente, una vuelta atrás en la situación provocada. En el momento de la expulsión del Paraguay del Mercosur, la medida no se extremó con el argumento de que no se quería castigar al pueblo paraguayo. Pero queda la posibilidad de que los activos intereses ruralistas brasileños hayan pesado en la decisión, más allá de lo proclamado públicamente. El actual peso de la bancada ruralista en el armado político de gobierno del segundo mandato de Dilma Roussef manifestado en el nombramiento de su emblemática y controvertida jefa, Kathia Abreu, como ministra de Agricultura, corroboraría esta línea de pensamiento. ${ }^{57}$

No es casual que haya sido un problema relacionado al agronegocio y, más específicamente, a esa simbiosis entre los terratenientes oligárquicos autóctonos y los brasiguayos, el hecho -construidoque actuó como excusa del juicio político para destituir al presidente Lugo. Luego de su primera actitud resignada, Lugo fue más claro en cuanto a su evaluación de lo ocurrido: "El caso Curuguaty es parte de la conspiración de los golpistas, que condujo a la parodia de juicio político que terminó con mi destitución". ${ }^{58}$ Recordamos que Curuguaty -aunque más exactamente Marina Kué- fue el lugar de la masacre orquestada para fundamentar la destitución de Lugo, ${ }^{59}$ lugar de gran capital simbólico para la resistencia

${ }^{56}$ Federico Franco, perteneciente al Partido Liberal y vicepresidente de Lugo, quedó como presidente luego de la destitución de éste y completó su mandato, desde junio de 2012 a agosto de 2013. Mucho antes del golpe parlamentario-judicial se había distanciado de Lugo y pasado a la oposición.

${ }^{57}$ Juan Luis Berterretche, "El enclave sojero de Sudamérica", Argenpress, 16 de septiembre de 2013.

${ }^{58}$ Fernando Lugo, "Carta abierta al pueblo paraguayo y a la comunidad internacional”, Paraguay Resiste, 2012.

${ }^{59}$ Borón, op. cit. La masacre de Curuguaty o de Marina Kue fue perpetrada el 
campesina: en él se mantuvo una importante presencia del campesinado frente al avance de la "revolución verde"; 60 allí también vivió muchos años el estandarte latinoamericano de otro modelo que daba al campesinado y a los pueblos indígenas un lugar privilegiado: José Gervasio de Artigas. Hay que reconocer que el caso Curuguaty produjo falsa pero eficazmente un doble efecto: desmovilizar al campesinado que tenía en frente una masacre que aparentemente respondía a una orden de $\operatorname{Lugo}^{61} \mathrm{y}$, por otro lado, hacer aparecer al mismo campesinado como capaz de atentar violentamente contra el Estado y los propietarios.

Martina Paredes, hermana de dos de los campesinos muertos en el hecho y hoy, quizás, una de las referentes claves de los familiares de las víctimas, nos decía: ${ }^{62}$

Esta era la sexta vez. Los anteriores desalojos fueron medio pacíficos; sí se fueron varia gente presos por eso [...] pero este último o sea que pensábamos que iba ser desalojo pacífico, pero se llegó con todo, con mucha fuerza. Yo por ejemplo estaba acá, yo sabía que mis hermanos estaban ahí cuando salí a la ruta como para trabajar me di cuenta que había demasiados policías y los helicópteros, las herramientas del Estado y hablaban mucho la gente de Campo Morombí, los personales, decían cosas: "acá va a morir gente" y eso a nosotros nos asustó. Al salir a la ruta te dabas cuenta que iba a ser diferente ese día, justamente lo que pasó. Nunca venían helicópteros para hacer un desalojo; inclusive la gente ahí pusieron un alambre. Hay un arroyito antes de llegar a cien metros pusieron alambre de púa y bandera paraguaya: -“¡no pasen eso, no pasen, respeten, vamos a hablar!”- “ ¡y no qué vamos a hablar!", inclusive echaron la bandera paraguaya que

15 de junio de 2013. En ella murieron once campesinos y seis policías. Estos hechos fueron la ocasión para el juicio de destitución que llevó a cabo el Congreso nacional acusando al presidente Lugo de ser su responsable clave. Sobre este tema: Coordinadora de Derechos Humanos del Paraguay, Informe de derechos humanos sobre el caso Marina kue, Asunción, CODEHupy, 2012.

${ }^{60}$ José Nicolás Morínigo, "La matriz histórica del problema de la tierra de la sociedad paraguaya”, NovaPolis, núm. 10, 2005, p. 11.

${ }^{61}$ Richer, "Seis preguntas y seis respuestas sobre la crisis paraguaya", p. 9.

${ }^{62}$ Las citas de las entrevistas que siguen fueron realizadas en el marco del trabajo del Observatorio de la Realidad Campesina e Indígena del Paraguay (ORCIP). 
pusieron la gente. Tenemos la foto, uno de los casos tenía la cabeza esparcida quiere decir que lo ejecutaron de cerca; mi hermano que tenía moretones tenía también disparo en la cabeza, a nosotros nos entregaron [los cuerpos] sin autopsia ni nada. ${ }^{63}$

Como nos decía José Tomás Benítez, dirigente del Asentamiento Comuneros y del Movimiento Agrario del Paraguay (MOAPA):

El caso Curuguaty es un caso mayor, emblemático para nosotros como organización y como país, como paraguayos. Para nosotros la discusión del Caso Curuguaty es una lucha que se tiene que aclarar por un lado y por otro lado que se tiene que juzgar a los responsables del caso Curuguaty y que se le dé a los compañeros la tierra que les pertenece a los compañeros. Y esa es nuestra lucha y nuestra reivindicación que estamos teniendo en debates y en discusiones y que queremos llevar hasta inclusive en el Congreso. Porque el problema nuestro, de nuestro país, es que la gente se olvida. El caso Curuguaty si no se va a hacer un tema de discusión permanente de la intervención, de la invasión masiva de la producción de los sojales, eso se va a quedar -como nosotros decimos acá- opareí. Un caso opareí se dice del que termina de balde, que termina así y no se sabe nada y no se profundiza nada. Creemos que el caso Curuguaty está yendo por ese camino y siempre vamos a reinvidicar. Ahí se plasmó la lucha del retroceso de la historia paraguaya y por eso es interesante para nosotros el caso Curuguaty. ${ }^{64}$

El auge indiscutible del agronegocio ha producido un fenómeno raro: mientras el gobierno de Lugo logró disminuir el índice de pobreza del país, los indicadores de pobreza e indigencia rural aumentaron aun siendo el sector campesino objeto privilegiado de los programas sociales. ${ }^{65}$ Esto habla de cómo en un país en que macroeconómicamente se crece, los mayores costos los paga el campesinado. Vera y Riquelme muestran cómo la concentración de la tierra aumentó hacia 2008, de manera que los índices son peores que los

${ }^{63}$ Martina Paredes, Yvypyta (Departamento Canindeyu), 19 de noviembre de 2014. ${ }^{64}$ José Tomás Benítez, Asentamiento Comuneros (Distrito Minga Guazú, Departamento Alto Paraná), 17 de agosto de 2013.

${ }^{65}$ Abente, op. cit., pp. 231-232. 
de 1991, cuando la salida de Stroessner todavía estaba fresca. ${ }^{66}$ Para sopesar este dato hay que tener en cuenta que ya en 2003 era el país con la distribución más desigual de la tierra en el mundo, ${ }^{67}$ con una tendencia creciente a la concentración. ¿Qué significó la democracia entonces como respuesta a la vida de los campesinos? Muy poco. Esto explica también que no hubo una respuesta rotunda del campesinado -el histórico actor político de cambio- frente a la caída de Lugo: la reforma agraria integral era su gran promesa y en su gobierno se terminó retrocediendo.

La expulsión del campesinado se da por la pobreza, ya que sin tierras y con una casi nula oferta laboral ${ }^{68}$ se da por la violencia y se da propiamente por la fumigación ${ }^{69}$ para los que quedan encerrados entre mares de soja. El campesino es para el agronegocio una de las principales plagas que hay que extirpar, y el Roundup $p^{70}$ también sirve para librarse de esa plaga. ${ }^{71}$

${ }^{66}$ Elsy Vera y Quintín Riquelme, "Cuenta regresiva para Lugo y la Reforma Agraria. Reforma agraria y desarrollo rural”, en Coordinadora de Derechos Humanos del Paraguay, Yvypóra Derécho Paraguáipe - Derechos Humanos en Paraguay 2011, Asunción, Codehupy, 2011, p. 266.

67 Tomás Palau Viladeslau, “'Políticas' agrarias en el Paraguay. Instrumentos de la discriminación”, NovaPolis, núm. 2, 2003, p. 6.

${ }^{68}$ Los brasiguayos dan poquísimo trabajo, y si lo dan, en general, traen gente de Brasil a trabajar. Ramón Fogel, "La guerra de la soja contra los campesinos en Tekojoja”, NovaPolis, núm. 10, 2005, p. 28.

${ }^{69}$ Vera y Riquelme, op. cit., p. 269.

70 Roundup es el nombre comercial del herbicida que fabrica la empresa Monsanto y que tiene como principal principio activo al glifosato. Por ser sistémico -y no selectivo- daña indiscriminadamente cualquier vegetal que entre en contacto con él. Este herbicida se relaciona directamente con el uso de las semillas transgénicas que son programadas, justamente, para ser inermes a él. Por tanto, podríamos decir que él daña todo menos a la planta programada transgénicamente. Se usa principalmente para el desmalezamiento del cultivo de soja. En nuestras visitas a las comunidades campesinas pudimos observar y escuchar el relato de cómo sus plantas morían o eran severamente dañadas por su aplicación en chacras linderas. Pudimos ver los naranjos -habituales en estas comunidades-, que ya no dan más fruto. También es atribuida a la acción del herbicida -que programa la muerte celular del ser vivo afectado- las muertes en aves, pérdidas de la preñez en animales y malformaciones en los seres humanos. Sólo entre 2010 y 2013 la importación de agroquímicos se quintuplicó (Rojas, op. cit., p. 88).

${ }^{71}$ Fogel, "Clases sociales y poder político en el Paraguay", Revista Novapolis, núm. 8, 2015, pp. 103-110. 
Don Celestino Chamorro, que dirige la radio comunitaria en Tavapy, en Alto Paraná, nos decía casi sin poder contener la emoción:

Me impresionó una señora con su esposo, que estaba ahí en la calle viviendo, tenían muchas gallinas y ahí en la calle vive, ¡bajo carpa! No sé cómo decirlo ... ¡está mal nuestro país!. ¡Se le persigue a los campesinos! El veneno que se tira a los arroyos ¡una vergüenza! -acá cerca en Ytakyry estuve escuchando un paraguayo que se estaba quejando-... matando sus gallinas, sus caballos ¡ya no pueden vivir más! ¡No saben qué hacer los paraguayos campesinos! ¡Denuncian y no se hace nada! $!^{72}$

Y Benítez nos decía sobre el mismo tema:

La situación de los compañeros que están al lado de la ruta bajo carpa con la idea y con la convicción de producir te demuestra, porque tiene sus gallinas, tiene sus vacas, igual ahí, bajo carpa, pensando en alguna vez que él pueda tener algún pedazo de tierra para desarrollar sus ideas, su sentimiento de producir y vivir con la tierra, con la madre naturaleza, con su familia completa hay alguno que bajo carpa se va a la escuela ahí en Tavapy II [...] Y bueno esa es la realidad paraguaya y una realidad latinoamericana $[\ldots]$ Que podamos desarrollar las ideas que nosotros tenemos programado de difundirle a nuestra gente, como pensamiento teórico, práctico y llenarle de conocimiento a nuestro compoblano paraguayo, campesino fundamentalmente, para que puedan desarrollar su pensamiento que hay una posibilidad sin pertenecer a un sector que reprime al pueblo todos los días y que le mantiene al pueblo bajo una represión permanente sin posibilidad de desarrollo y de pensamiento diferente. ${ }^{73}$

Lindolfo Martínez, también dirigente del asentamiento Santiago Martínez, en Alto Paraná, y del Movimiento Campesino Paraguayo

72 Chamorro, Celestino, Tavapy (Departamento Alto Paraná), 2 de octubre de 2014.

73 Asentamiento Comuneros (Distrito Minga Guazú, Departamento Alto Paraná), 2 de octubre de 2014. 
(MCP) nos habla de la represión a la libertad de expresión y a la organización comunitaria campesina: "El gobierno prohibió por ley la radio comunitaria. Nosotros pensamos que este es un gobierno de una nueva dictadura, estricto como está cumpliendo la receta del Fondo Monetario". ${ }^{74}$

Una vieja pregunta se hace hoy agónica: "El campesino ¿tiende a extinguirse y proletarizarse o a asumir nuevas formas ampliando y recreando su identidad y acción colectiva?". ${ }^{75}$ Formulada de otra manera: ¿puede convivir -y si es así, cómo- algún tipo de reforma agraria con el modelo del agronegocio? ${ }^{76}$

\section{LA INTERVENCión de Estados Unidos}

La presencia dominante de Estados Unidos en los estamentos oligárquicos del Paraguay es una humillante realidad para el pueblo paraguayo especialmente desde que Stroessner, desde el comienzo de su mandato, eligió colocar su proclamado "nacionalismo" bajo la égida imperial yanqui. Por eso, constituye otro de los aspectos claves del "stronismo globalizado", que, aunque siempre vivo, reverdecerá con el gobierno de Cartes.

Ese dominio humillante tuvo -y tiene-sus expresiones más alevosas en el atropello -con masacres y torturas incluidas- sobre la población campesina e indígena. Pero se extiende a cualquier sector que amague, siquiera, una disonancia al dominio capitalista.

Esta presencia continuó con un "bajo perfil" -como ellos mismos lo definen- bajo el gobierno de Lugo, subsidiando económica y "académicamente" la formación de las fuerzas de seguridad, ${ }^{77} \mathrm{fi}$ nanciando a la Corte Suprema, papel que públicamente reconoce

${ }^{74}$ Entrevista en Distrito Santa Fe, Departamento Alto Paraná, 16 de octubre de 2014.

${ }^{75}$ Fernando Calderón y Elizabeth Jelin, Clases y movimientos sociales en América Latina: perspectivas y realidades, Buenos Aires, CEDEs, 1987, p. 20.

${ }^{76}$ Richer, Paraguay: fin de un período histórico, p. 21.

77 Natalia Viana, "El papel de los Estados Unidos en la caída de Lugo", E'a. Periódico de Interpretación y Análisis, Asunción, 8 de febrero de 2013. 
la USAID $^{78}$ (2013), la misma USAID que, según Nickson, ${ }^{79}$ subsidiara y organizara el horrendo aparato represivo de Stroessner. La presencia norteamericana en Paraguay es estratégica:

Desde antes de septiembre de 2001, los mandos militares de EE. UU. están interesados en tener posiciones en esta zona, que además de su riqueza natural es vista como cuña para desactivar cualquier proyecto entre Argentina y Brasil que prescinda de la mediación de EE. UU. o de sus políticas continentales impulsadas por los organismos regionales $[\ldots] .{ }^{80}$

Paraguay es una pieza importante en el tablero militar. Por muchas razones. Porque tiene una extensa y difícilmente controlable frontera con Brasil: porque sus élites militares y económicas son corruptas y fácilmente manipulables: porque Brasil depende de la energía de Itaipú y Argentina de Yaciretá; [...] En suma, Paraguay presenta un doble interés: la ubicación geográfica y las características políticas, que lo convierten en un país importante para poder desestabilizar a Brasil. ${ }^{81}$

Uno de sus objetivos es la profundización de su inserción militar en un lugar clave para la teoría geopolítica: el Chaco Paraguayo (dentro de aquel famoso Hinterland) y su inmediato acceso al Acuífero Guaraní, encima del cual está asentado el enclave sojero brasiguayo. Entre muchos elementos conviene recordar dos cosas sobre la injerencia norteamericana. La primera: tras el golpe hubo varias manifestaciones de que se quería activar la relación con Estados Unidos ("liberado" el Paraguay de su amarre a los organismos latinoamericanos); una de ellas fue del diputado López Chávez, quien manifestó haber pedido que el Comando Sur norteamericano

${ }^{78}$ La agencia estatal norteamericana presentada como de ayuda a los países no desarrollados.

${ }^{79}$ Nickson, op. cit., p. 289.

${ }^{80}$ Ana Esther Ceceña y Carlos Ernesto Motto, "Paraguay: eje de la dominación del Cono Sur", Revista OSAL, vol. 6, núm. 17, 2006, p. 278.

${ }^{81}$ Raúl Zibechi, "Introducción", en Cristina Coronel et al., USAID en Paraguay. La asistencia como estrategia de dominación, Asunción, BASE-IS/Fundación Rosa Luxemburgo, 2012, p. 20. 
instalara una base militar en el país. ${ }^{82}$ La segunda es que el día de la elección se dio publicidad a dos "hechos" misteriosos; uno, la detención de dos bolivianos (uno presunto miembro de fuerzas de seguridad de ese país) que venían con la supuesta misión de atentar contra Cartes; y otro, un llamativo "atentado" del EPP en el norte con un policía y un supuesto "guerrillero" muerto que toda la población local sostuvo que no tuvo nada que ver. Estos dos elementos se ubicaron sospechosamente en la línea de justificar la militarización "antiterrorista", con ocupación del norte paraguayo y fortalecimiento de la "necesidad" de instalar una base norteamericana en la región del Chaco, ${ }^{83}$ ante la ridícula "hipótesis de conflicto" con Bolivia.

La serie de intereses norteamericanos en el golpe y en la posterior institucionalización oligárquica se relaciona también con el accionar de las empresas de agronegocio como Monsanto y del oportunismo de la ganancia desorbitada como Río Tinto Alcán. Los intereses de Monsanto, especialmente en la estratégica aprobación de sus semillas transgénicas para el algodón -que barre con uno de los cultivos emblemáticos del campesinado y lo pone en manos del agronegocio- y sus lazos políticos, especialmente con el coloradismo y Cartes, están descritos en los textos de Méndez Grimaldi. ${ }^{84}$ La empresa canadiense Río Tinto Alcán pretendía fabricar aluminio en Paraguay basándose exclusivamente en la posibilidad de obtener energía baratísima allí; allí no hay ni materia prima para el aluminio, como la bauxita, ni tampoco mercado de venta. Se acapararía la mitad de la energía que le corresponde al Paraguay por Itaipú, lo que iba a significar un cierre de cualquier extensión del

82 Telma Luzzani, Territorios vigilados. Cómo opera la red de bases militares norteamericanas en Sudamérica, Buenos Aires, Debate, 2012.

${ }^{83}$ Cuando se habla de una base norteamericana en Paraguay, se alude normalmente a Mariscal Estigarribia (Departamento Boquerón), donde los norteamericanos construyeron la pista de aterrizaje más grande de Sudamérica, preparada para recibir los más avanzados aviones de guerra (que evidentemente los tiene Estados Unidos) y mantienen una dotación militar de aquel país.

${ }^{84}$ Méndez Grimaldi, "Los intereses convergentes que derrocaron a Lugo"; "Monsanto golpea en Paraguay: los muertos de Curuguaty y el juicio político a Lugo", 2012. 
servicio eléctrico a la población paraguaya y, a la vez, de cualquier proyecto serio de industrialización nacional. ${ }^{85}$

Esta intervención norteamericana ya configura al "modelo Honduras" como relativamente exitoso y aplicable para su ambición de dominación del "patio trasero", el cual tiene como denominador común: 1) las características contramayoritarias de los poderes legislativo y judicial; 2) el accionar de los medios de comunicación hegemónicos promoviendo primero y legitimando después; 3) cierta desmovilización de la población; 4) un accionar "acotado" de las Fuerzas Armadas y de seguridad, por lo menos en relación a las antiguas dictaduras; 5) la "neutralidad" discursiva norteamericana acompañada de un fuerte proactivismo de sus diplomáticos y enviados; 6) la inutilidad de la Organización de Estados Americanos (oEA), cuya ineficacia en estos casos dio pie a sospechas de colaboración. ${ }^{86}$

\section{LA INTEGRACIÓN LATINOAMERICANA EN JAQUE}

La importante disonancia que, en principio, se preveía en las políticas paraguayas frente a sus ahora cuatro compañeros del Mercosur traía aparejada una serie de interrogantes y previsibles dificultades al proceso de integración. Esto se entiende porque fue lo político lo que marcó este proceso después del renovado rumbo que tomó tras la Cumbre de Mar del Plata que enterró el ALCA ${ }^{87}$ en 2005.

Como primer dato está el de un Paraguay plenamente sometido a los dictados de Estados Unidos. La acción norteamericana guarda, aparentemente, cierta discreción para no chocar frontalmente con los otros países del bloque, pero parece tener allanados todos los caminos para actuar de parte del gobierno colorado. Es éste uno de los elementos centrales del "stronismo globalizado"

85 Cf. Brian Turner, "Paraguay: la vuelta del Partido Colorado al poder", Revista de Ciencia Política, vol. 34, núm. 1, 2014, p. 253.

${ }^{86}$ Soler, "Golpe de Estado y derechas en el Paraguay. Transiciones circulares y restauración conservadora”, Nueva Sociedad, núm. 254, 2014, pp. 73-74.

${ }^{87}$ La Alianza de Libre Comercio de las Américas, propugnada desde Estados Unidos. 
del que hablábamos. La dificultad es ésta: el sometimiento imperialista de Stroessner en relación a Estados Unidos funcionó en fuerte sintonía con el subimperialismo brasileño. ${ }^{88}$ Ese escenario no parece totalmente reproducible actualmente. Lo que ha cambiado fuertemente es el contexto regional y en forma relevante en lo que hace al Brasil.

Un segundo dato es lo que podríamos llamar "responsabilidad" de los otros países del Mercosur en la situación paraguaya, la cual es compartida pero predominantemente brasileña. Una mirada profunda hacia el problema del campesinado y las comunidades indígenas paraguayas, además de mostrar un problema de injusticia socio-económica y de insustentabilidad de un modelo de desarrollo protagonizado por la "revolución verde", exige también una actitud de defensa de los derechos humanos afectados por la repetida actividad delictiva de muchos de los actores del agronegocio. ${ }^{89}$ El dilema planteado es que si los demás países del Mercosur se animan a analizar profundamente y actuar en torno al fenómeno paraguayo, tendrán que mirar también hacia adentro de sus fronteras y enfrentar con claridad este tipo de problemas que también se dan, de distintas maneras, en sus propios países. Hasta el momento esa actitud no fue visible; y es, posiblemente, inexistente.

En cuanto al tema brasiguayo se puede afirmar que hay una simbiosis entre el latifundista patrimonialista tradicional paraguayo y la concentración brasiguaya en el oriente. Esta simbiosis tiene la doble función de enriquecer a la oligarquía prebendaria autóctona y de posibilitar la ocupación brasiguaya motorizadora del agronegocio.

La brasileñización del oriente paraguayo fue potencializada -además de por la desigualdad inicial frente a los colonos paraguayos- con los picos relacionales que Stroessner logró con Kubitschek y Castelo Branco, y creció exponencialmente con la "revolución verde" centrada en la soja.

${ }^{88}$ Cecilia Vuyk, Subimperialismo brasileño y dependencia del Paraguay. Los intereses detrás del golpe de 2012, Asunción, CyP. 2014.

${ }^{89}$ Fogel, "La guerra de la soja contra los campesinos en Tekojoja”, p. 33. 
Es oportuno observar, según el interesante trabajo de Kohlhepp,${ }^{90}$ cómo las características centrales de este fenómeno fueron delineadas durante el stronismo y se fueron acrecentando en forma geométrica. Una primera característica, apuntada ya, de la desigualdad de los actores se manifiesta en el acceso a los títulos definitivos de tierra y al crédito, ayudada por la corrupción de los agentes estatales. Otra es la participación de grandes empresas brasileñas del agronegocio, activas a ambos lados de la frontera, que con su aporte tecnológico y consiguiente mínimo requerimiento de mano de obra, van concentrando tierras que ya han sido objeto del "trabajo sucio" (desmonte, quita de raíces, infraestructura básica, etc.) de colonos paraguayos. Así los simulacros de "reforma agraria" que fueron algunos planes de colonización a favor de paraguayos redundaron en un trabajo más barato para los grandes sojeros brasileños. Un tercer elemento es la simbiosis local de este modelo productivo con el tradicional contrabando, ya que grandes cantidades de productos (soja principalmente) son traídos desde Brasil para liquidarlos en Paraguay -con casi nula carga impositiva- y exportarlos como producto paraguayo desde puertos brasileños. ${ }^{91}$

${ }^{90}$ Gerd Kohlhepp, "Colonización y desarrollo dependiente en el oriente paraguayo”, Revista Geográfica, núm. 99, 1984, pp. 5-33.

${ }^{91}$ Sobre el tema del contrabando de soja no he encontrado estudios académicos específicos; sí claras y valiosas referencias, sumado a notas periodísticas. El tema relaciona contrabando proveniente tanto de Argentina como de Brasil y está relacionado al lavado de dinero y al narcotráfico, por lo menos en buena parte. El tema es de gran importancia ya que tiene varias consecuencias: 1) develar el carácter mafioso de buena parte del agronegocio en la frontera paraguayo-brasileña y del empresariado asociado al mismo (a los dos lados de la frontera); 2) modificar claramente los números productivos que son expuestos sobre la producción paraguaya de soja, ya que hay declaraciones que refieren que un tercio de la soja declarada como paraguaya es producida en otros países ( $c f$. Javier Álvarez, "De productores argentinos de soja a contrabandistas". Contrainfo. Periodismo para pensar. http://www.contrainfo.com/12657/de-productores-argentinos-de-soja-a-contrabandistas/...). Algunos trabajos académicos que se refieren al tema: Camilo Pereira Carneiro Filho, "Tríplice Fronteira Brasil-Argentina-Paraguai: transfronteirizacao através do crime”, Relações Internacionais no Mundo Atual, vol. 2, núm. 16, 2012, pp. 383-400; Figueira, Ariane Cristine Roder, "Relacoes diplomáticas Brasil -Paraguai e o problema do crime organizado transfonteiriço", Meridiano 47, vol. 11, núm. 118, mayo, pp. 30-32; Rogério Haesbaert, "Regios transfronteiricas e redes 
Un cuarto elemento es la indescriptible destrucción ambiental centrada en la acelerada desaparición boscosa con indiferencia total a cualquier reglamentación y acompañada de impunidad, acicateada por el contrabando de madera hacia Brasil, hecho que causó un enorme daño en los cursos de agua y su repercusión en las comunidades indígenas, que, encima, vienen siendo "perseguidas y aniquiladas hasta en sus zonas de retiro desde fines de los años 1960" ${ }^{92}$ Esto es posible dentro de un cuadro de lo que suele denominarse "ausencia del Estado", ${ }^{93}$ que, más bien, habría que entender como falta de servicios a favor de la población, porque, en realidad, a la hora de la represión frente a reclamos de justicia social, el Estado paraguayo está presente, hasta sobreabundantemente, como se evidenció en Marina Kué.

Así, por las características del circuito de comercialización orientado externamente en forma plena, se plantea la existencia de un enclave ${ }^{94}$ que va minando iniciativas de producción y organización por parte de los campesinos paraguayos.

Entrevistamos a Fermín Bobadilla, dirigente del asentamiento Santiago Martínez, en el distrito de Santa Fe, integrante del Movimiento Campesino Paraguayo (MCP) y Concejal Departamental de Alto Paraná por el Frente Guasu, quien proviene de una familia de militantes de las Ligas Agrarias, ya que su padrastro -Juan de Dios Salinas- fue desaparecido durante el régimen stronista:

Con este gobierno es dura la cosa. Ahora la gente está sintiendo mucho. Este gobierno no es un gobierno débil, no es Lugo, ni otro gobierno colorado. Aparte de que no tiene programa ni proyecto ni siquiera hablan del campesinado, de la producción [...] Este gobierno ni siquiera habla de cómo van a acompañar a los pequeños productores, no tienen ningún plan. Se basa fundamentalmente en las privatizaciones, de las tierras, aeropuertos, tema naval, todas esas

‘brasileiras' no Mercosul”, 2015; Argemiro Procópio, “A integração continental pelo narcotráfico".

${ }^{92}$ Kohlhepp, op. cit., p. 22.

${ }^{93}$ Jacinto Santa María, "Nuevas amenazas, hipótesis de conflicto y política de defensa en el Paraguay", Arbeitspapiere des IKK, núm. 24, 2005.

${ }^{94}$ Fogel, "La guerra de la soja contra los campesinos en Tekojoja”, p. 27. 
cosas. Y ahora el gobierno está impulsando eso, en todas partes; entonces va a ser difícil de un desarrollo económico en nuestro país si no hay un impulso a la producción agrícola y pecuaria, porque los grandes productores ya sea de agrícola o pecuaria no invierten acá, sino más bien utilizan como espacio de siembra y después lo que sale en el ámbito del ganado también. Entonces si no hay inversión, es difícil un crecimiento económico. La gente está sintiendo y va a sentir más el golpe económico. [...] Lo más grave es que no están aparte los poderes: un senador también es latifundista. ${ }^{95}$

\section{CONSIDERACIONES FINALES}

Retomando lo analizado, se sostiene que el golpe parlamentariojudicial de 2012 en Paraguay, que abrió paso a la presidencia del liberal Federico Franco y la posterior elección y los pasos dados por el gobierno colorado de Horacio Cartes evidencian la vigencia de un modelo al que denomina "stronismo globalizado", cuyas características en cuanto a política interna son una continuidad relativamente actualizada de la estructuración y las prácticas políticas de dominación que estableció el general Stroessner y su régimen en el país. Entre los componentes de esta caracterización destaca la forma de implementar, a la vez, una percepción de omnipotencia en la dominación que tiene su contracara en la simultánea percepción de impotencia popular, ambas enlazadas con una violencia hacia los sectores populares unida a una dosis de paternalismo patronal para una parte de la población. Se afirma también la vigencia del triángulo Fuerzas Armadas-Partido Colorado y gobierno, aunque con el crecimiento de la presencia empresarial como determinante mayor. Un tercer elemento es la articulación entre la corrupción institucionalizada, la lógica clientelista y el intento -relativamente exitoso- del logro de un consenso pasivo en la población. Un cuarto es la configuración de una "oposición" partidaria que comparte las grandes líneas de esta praxis política y del modelo económico a

${ }^{95}$ Fermín Bobadilla, Santiago Martínez (Distrito Santa Fe, Departamento Alto Paraná), 16 de octubre de 2014. 
imponer. Y sobre este punto se destaca cómo este modelo se basa en una política que intenta aunar la promoción de un proceso de descampesinización, el crecimiento del agronegocio, el crecimiento macroeconómico y una distribución regresiva del ingreso.

Este tipo de política interna nos expresa con particular vivacidad el dilema de la democracia formal, procedimental. El stronismo terminó configurando, al decir de Richer, ${ }^{96}$ "una democracia conservadora a la medida de una burguesía fraudulenta que asumiendo lealtad con el partido y el modelo, pudo eludir sus compromisos con el Estado" (aunque, personalmente no llamaría "democracia" a este engendro, ni "burguesía” al colectivo empresarial paraguayo). Cuando hay una situación de desaliento y de desmovilización / desmotivación, las posibilidades de que las estructuras clientelares impongan a fuerza de dinero y presión su voluntad son mucho mayores, y en ese caso queda seriamente en duda una identificación inmediata de un resultado electoral con la expresión de la voluntad popular. La reflexión sobre esta realidad de la democracia paraguaya nos permite pensar - proyectando estos temas a la realidad regional-en tres grandes deudas pendientes si es que queremos hablar de una época posneoliberal latinoamericana: primero, la presencia acechante de las neooligarquías que con la colaboración norteamericana conservan un grado importantísimo de poder en todos los países y en este tipo de circunstancias aprovechan para plasmarlo institucionalmente y obstaculizar el proceso de integración latinoamericano; segundo, la necesidad de trabajar en el interior de los gobiernos que se proclaman -y en gran parte lo son- como populares en la región para profundizar un proceso de movilización política autodeterminante que vaya apagando los focos de clientelismo que están vivos dentro de las propias fuerzas que los apoyan; tercero, la definición de un modelo de desarrollo que no esté basado en el extractivismo y reprimarización de la economía y -especialmente para los países del Cono Sur- en el agronegocio. Dicho modelo, comprendiendo al campesinado y a las comunidades indígenas, como un sujeto político clave, debería valorarlos en su proyección "como fuerzas culturales alternativas en las sociedades

${ }^{96}$ Richer, Paraguay: fin de un período histórico, p. 5. 
capitalistas". ${ }^{97} \mathrm{La}$ "función social y económica" de la tierra, la reforma agraria y el desaliento al latifundio son mucho más constitucionales que el procedimiento con el cual se tumbó el gobierno Lugo.

Como había afirmado Laclau, ${ }^{98}$ el neoliberalismo es el peligro mayor para nuestras democracias. Este es un caso patente de ese peligro. La reflexión política latinoamericana debe seguir creciendo, desde perspectivas propias, en expresar clara y evidentemente este hecho para pensar en democracias que expresen la voluntad popular y se concreten en democratización económico-social en nuestros países. Es un desafío hermosamente posible en este tiempo latinoamericano, pero como lo demuestra el caso paraguayo, no logrado todavía y no tan fácil de lograr.

El modelo de inserción internacional de este "stronismo globalizado" expresa también parte de las contradicciones que existen en gobiernos latinoamericanos que defienden una pretensión de autonomía en su política externa y una defensa de la integración regional como núcleo de la misma. Los procesos y organismos de integración latinoamericanos tendrán que enfrentar una dura disputa frente a estas tendencias que el modelo del gobierno paraguayo hace patentes, y ese será un gran desafío para el camino que venía llevándose en los últimos diez años. Una postura inteligente, clara, que frente a la pretensión de primacía norteamericana en la región es uno de los elementos a discutir y definir.

Paraguay se puso colorado. Este modelo tiene posibilidades de triunfo y ese 21 de abril de las elecciones lo demostró. Frente a esta realidad, la potenciación del sujeto político de un posible, pero todavía no tan real, posneoliberalismo y del proceso de integración regional que debe operar como contexto, es clave para enfrentar esa posibilidad, para que no se pongan colorados otros países de América Latina, para que sea posible desde América Latina ofrecer al mundo una alternativa epistémico-política propia que evite la vergüenza de la dominación de los más poderosos.

${ }^{97}$ Calderón y Jelin, op. cit., p. 31.

${ }^{98}$ Ernesto Laclau, "La deriva populista y la centroizquierda latinoamericana", Nueva Sociedad, núm. 205, 2006, p. 61. 


\section{BibliogRAFíA}

$A B C$ Color, "Ni piensan en base militar de EEUU, según ministra", Asunción, 12 de julio de 2012.

Abente Brun, Diego, "Paraguay: Crecimiento económico, conflicto social e incertidumbre política”, Revista de Ciencia Política, vol. 32, núm. 1, 2012, pp. 229-244.

Álvarez, Javier, "De productores argentinos de soja a contrabandistas", Contrainfo. Periodismo para pensar, http://www.contrainfo.com/12657/ de-productores-argentinos-de-soja-a-contrabandistas /

Amado, Najeeb, "Modelo Cartes y razón de Argaña”, E’A. Periódico de Interpretación y Análisis, Asunción, 6 de abril de 2013.

ANR. Asociación Nacional Republicana. Partido Colorado, Líderes: Alfredo Stroessner, http:/ / www.anr.org.py/paginas.php?cod=29

Ansaldi, Waldo, "Frívola y casquivana, mano de hierro en guante de seda. Una propuesta para conceptualizar el término oligarquía”, 1991, http:/ / www.catedras.fsoc.uba.ar/udishal

Arditi, Benjamín, "Adiós a Stroessner: nuevos espacios, viejos problemas", Nueva Sociedad, núm. 102, 1989, pp. 24-32.

Berterretche, Juan Luis, "El enclave sojero de Sudamérica", Argenpress, 16 de septiembre de 2013, http:/ / www.argenpress.info/2013_09_16_archive.html

Borón, Atilio, “`Por qué cayo Lugo?”, Página/12, Buenos Aires, 24 de junio de 2012.

Cáceres Mercado, Sergio, "Como ovejas al matadero", Última hora (Asunción), 15 de abril de 2013.

Calderón, Fernando y Elizabeth Jelin, Clases y movimientos sociales en América Latina: perspectivas y realidades, Buenos Aires, CEDEs, 1987.

Carneiro Filho, Camilo Pereira, "Tríplice Fronteira Brasil-Argentina-Paraguai: transfronteirizacao através do crime”, Relações Internacionais no Mundo Atual, vol. 2, núm. 16, 2012, pp. 383-400.

Ceceña, Ana Esther y Carlos Ernesto Motto, "Paraguay: eje de la dominación del Cono Sur”, Revista OSAL, vol. 6, núm. 17, 2006, pp. 275-288.

Coordinadora de Derechos Humanos del Paraguay (Codehupy), Informe Chokokue 1989-2013. El plan sistemático de ejecuciones en la lucha por el territorio campesino, Asunción, SV Servicios Gráficos, 2014. 
, Informe de derechos humanos sobre el caso Marina kue, Asunción, CODEHUPY, 2012.

Coronel, Cristina et al., USAID en Paraguay. La asistencia como estrategia de dominación, Asunción, BASE-IS/Fundación Rosa Luxemburgo, 2012.

Duarte Recalde, Liliana Rocío, “Concentración del poder político y debilitamiento estatal durante el gobierno de Cartes”, Revista Novápolis, núm. 7, abril-octubre de 2014, pp. 37-52.

El Mercurio, "Magnate paraguayo, favorito para las presidenciales, promete retorno al poder del Partido Colorado", Santiago de Chile, 24 de marzo de 2012.

Figueira, Ariane Cristine Roder, "Relacoes diplomáticas Brasil-Paraguai e o problema do crime organizado transfonteiriço", Meridiano 47, vol. 11, núm. 118, mayo de 2010, pp. 30-32Fogel, Ramón, "La guerra de la soja contra los campesinos en Tekojoja”, NovaPolis, núm. 10, 2005, pp. 26-34.

—_, "Clases sociales y poder político en el Paraguay", Revista Novapolis, núm. 8, 2015, pp. 103-110.

Freitas, Carolina, "Partido Colorado: 'A saída de Lugo foi queda de um modelo'”, Veja, São Paulo, 26 de junio de 2012.

Haesbaert, Rogério, "Regios transfronteiricas e redes 'brasileiras' no Mercosul”, 2015, http://observatoriogeograficoamericalatina.org.mx/ egal8/Geografiasocioeconomica/Geografiaregional/04.pdf

Irala, Oscar, "Siete reflexiones en torno al asesinato del ganadero y la supuesta autoría del EPP”, Servicio Paz y Justicia Paraguay, 2015, en http: //www.serpajpy.org.py/?p=1290

Kohlhepp, Gerd, "Colonización y desarrollo dependiente en el oriente paraguayo”, Revista Geográfica, núm. 99, 1984, pp. 5-33.

Korol, Claudia, "Paraguay, la resistencia popular y las guerras del imperio", América Libre, 2006, en http://www.nodo50.org/americalibre/ novedades/korol_250706.pdf

Laclau, Ernesto, "La deriva populista y la centroizquierda latinoamericana”, Nueva Sociedad, núm. 205, 2006, pp. 56-61.

Lugo, Fernando, "Carta abierta al pueblo paraguayo y a la comunidad internacional", Paraguay Resiste, 2012, http://paraguayresiste.com/ caso-curuguaty-carta-abierta-de-lugo-al-pueblo-paraguayo

Luzzani, Telma, Territorios vigilados. Cómo opera la red de bases militares norteamericanas en Sudamérica, Buenos Aires, Debate, 2012. 
Marchini, Helena y Pablo Nuño Amoedo, entrevista al exministro paraguayo Hugo Ruiz Díaz Balbuena: "Paraguay está hoy subordinado a los intereses de los Estados Unidos”, América Latina en movimiento, 3 de agosto de 2015, http:/ / www.alainet.org/es/articulo/171510

Méndez Grimaldi, Idilio, "Los intereses convergentes que derrocaron a Lugo", La Jornada, 25 de junio de 2012.

_ juicio político a Lugo", 2012, http:/ / www.rebelion.org/docs/151721. pdf

Morínigo, José Nicolás, "La matriz histórica del problema de la tierra de la sociedad paraguaya”, NovaPolis, núm. 10, 2005, pp. 5-12.

Nickson, Robert Andrew, "El régimen de Stroessner (1954-1989)", en A.V., Historia del Paraguay, Asunción, Ignacio Telesca, 2010, pp. 265-294.

Obando Jaramillo, Valentina, "Colombia entrena paraguayos para combatir el EPP”, El Espectador (Bogotá), 8 de agosto de 2015.

Palau, Marielle, "Los intentos del Plan Colombia para seguir avanzando en Paraguay", en Marielle Palau (coord.), Criminalización a la lucha campesina, Asunción, BASE-IS/Fundación Rosa Luxemburgo, 2009, pp. 23-.

Palau Viladeslau, Tomás, “'Políticas' agrarias en el Paraguay. Instrumentos de la discriminación”, NovaPolis, núm. 2, 2003, pp. 3-23.

Peregil, Francisco, "Paraguay, el paraíso de la corrupción electoral", El País, Madrid, 20 de abril de 2013.

Pereira Cardozo, Hugo Javier, El EPP, defensa reaccionaria de un modelo de desarrollo desigual y excluyente, Buenos Aires, clacso, 2015.

Procópio, Argemiro, “A integração continental pelo narcotráfico”, http:// www.iri.edu.ar/revistas/revista_dvd/revistas/R17/A\%20integra. htm

Rehnfeldt, Mabel, "Narcocoloradismo", ABC Color, Asunción, 15 de julio de 2012.

Richer, Hugo, Paraguay: fin de un período histórico, Asunción, BASE Investigaciones Sociales, 2008.

-, "Seis preguntas y seis respuestas sobre la crisis paraguaya", Nueva Sociedad, núm. 241, 2012, pp. 4-11.

Rodríguez, José Carlos, "El cambio frágil del Paraguay. La esperanza y las dificultades de Fernando Lugo", Nueva Sociedad, núm. 220, 2009, pp. 4-14. 
Rojas Villagra, Luis, La metamorfosis del Paraguay. Del esplendor inicial a su traumática descomposición, Asunción, BASE-IS /Fundación Rosa Luxemburgo, 2014.

Romano, Silvina, "Democracia liberal y seguridad nacional en el gobierno estadounidense: continuidades y rupturas", en Marco A. Gandasegui, hijo y Dídimo Castillo Fernández (coords.), Estados Unidos: la crisis sistémica y las nuevas condiciones de legitimación, México, CLAcsoSiglo XXI, 2010, pp. 360-384.

Sánchez, José Tomás, "El campesino paraguayo es pobre porque es ignorante. El discurso legítimo de los medios escritos de comunicación y la lucha por la tierra", en Marielle Palau (coord.), Criminalización a la lucha campesina, Asunción- BASE-IS / Fundación Rosa Luxemburg, 2009, pp. 103-133.

Santa María, Jacinto, "Nuevas amenazas, hipótesis de conflicto y política de defensa en el Paraguay", Arbeitspapiere des IKK, núm. 24, 2005.

Schurster, Karl y Márcio Oliveira de Brito, "Entre a Alternância e a Hegemonia Política: o Paraguai no Tempo Presente", Boletim Historiar, núm. 02, 2014, pp. 07-18.

Segovia, Diego, "Paraguay 2013: los medios y el consenso reaccionario", Perspectivas, núm. 13, 2013.

Soler, Lorena, "Dominación política y legitimidad. El stronismo en el contexto de América Latina”, NovaPolis, núm. 4, 2009, pp. 77-99.

, "Golpe de Estado y derechas en el Paraguay. Transiciones circulares y restauración conservadora”, Nueva Sociedad, núm. 254, 2014, pp. 73-83.

Soler, Lorena y Gustavo Torre, Balance del gobierno del empresario Horacio Cartes en Paraguay, CELAG, 2015, http://www.celag.org/balance-del-gobierno-del-empresario-horacio-cartes-en-paraguay/

Strasser, Carlos, Democracia E Desigualdad. Sobre la "democracia real" a fines del siglo xx, Buenos Aires, Clacso, 1999.

Tokatlian, Juan Gabriel, "América Latina, China y Estados Unidos. Un triángulo promisorio”, Revista CIDOB d'Afers Internacionals, núm. 78, 2007, pp. 187-195.

Turner, Brian, "Paraguay: la vuelta del Partido Colorado al poder", Revista de Ciencia Política, vol. 34, núm. 1, 2014, pp. 249-266.

USAID/Paraguay, "Historia de la asistencia de los Estados Unidos en Paraguay", 2013, http://paraguay.usaid.gov/es/node/54 
Varela, Julia y Federico Larsen, "El trabajo periodístico en Paraguay: el golpe de Estado en 2012 y los medios de resistencia al discurso hegemónico", Oficios Terrestres, vol. I, núm. 29, 2013, http://perio.unlp. edu.ar/ojs/index.php/oficiosterrestres/article/view/1961/1760

Vera, Elsy y Quintín Riquelme, "Cuenta regresiva para Lugo y la Reforma Agraria. Reforma agraria y desarrollo rural”, en Coordinadora de Derechos Humanos del Paraguay, Yyypóra Derécho Paraguáipe Derechos Humanos en Paraguay 2011, Asunción, Codehupy, 2011, pp. 267-272.

Viana, Natalia, "El papel de los Estados Unidos en la caída de Lugo", E'a. Periódico de Interpretación y Análisis, Asunción, 8 de febrero de 2013.

Vuyk, Cecilia, Subimperialismo brasileño y dependencia del Paraguay. Los intereses detrás del golpe de 2012, Asunción, CyP. 2014.

Winer, Sonia, "Cartismo en Paraguay: militarización y vulneración de derechos en el contexto regional", Jornadas de Sociología 2015-Universidad de Buenos Aires, 2015, en http://jornadasdesociologia2015.sociales.uba. ar/wp-content/uploads/ponencias/1063_88.pdf

-, La estrategia de Estados Unidos y su proyección sobre América del Sur, Buenos Aires, Escuela de Defensa Nacional, 2013.

Winer, Sonia y Lucas Melfi, "Guerra contra el Ejército del Pueblo Paraguayo: impacto durante el gobierno de Cartes", en VIII Jornadas de Sociología de la Universidad Nacional de La Plata, 2014, http://jornadassocio logia.fahce.unlp.edu.ar/viii-jornadas-2014/PONmesa21Wi ner.pdf

Zibechi, Raúl, "Introducción”, en Cristina Coronel et al., USAID en Paraguay. La asistencia como estrategia de dominación, Asunción, BASE-IS/Fundación Rosa Luxemburgo, 2012, pp. 15-22.

\section{Entrevistas}

Benítez, José Tomás, Asentamiento Comuneros (Distrito Minga Guazú, Departamento Alto Paraná), 17 de agosto de 2013.

—- Asentamiento Comuneros (Distrito Minga Guazú, Departamento Alto Paraná), 2 de octubre de 2014.

Bobadilla, Fermín, Santiago Martínez (Distrito Santa Fe, Departamento Alto Paraná), 16 de octubre de 2014. 
Chamorro, Celestino, Tavapy (Departamento Alto Paraná), 2 de octubre de 2014.

Martínez, Lindolfo, Santiago Martínez (Distrito Santa Fe, Departamento Alto Paraná), 16 de octubre de 2014.

Paredes, Martina, Yvypyta (Departamento Canindeyu), 19 de noviembre de 2014. 